\title{
Alvarado score: can it reduce unnecessary interventions for acute appendicitis in children?
}

${ }^{1}$ Emergency County Hospital Piatra Neamt

${ }^{2}$ Faculty of Medicine, University “Ovidius” of Constanta

\begin{abstract}
The purpose of the study is to compare the outcomes of surgical interventions for acute appendicitis with the values of the Alvarado score.

We conducted the study on 572 patients that underwent surgical interventions for acute appendicitis. Retrospectively, based on the medical records, we calculated the MANTRELS score and compared the outcomes of the intervention with the values of the applied score. Almost one third of the patients with a MANTRELS score lower than 6 had negative appendectomies. These patients represent $60 \%$ of the total cases of negative appendectomies, while in the case of patients with a high score around $2 \%$ had negative appendectomies.

We concluded that using this scoring system to assess the need of immediate surgical intervention is important and can increase the rate of positive diagnosis mainly by limiting the number of unnecessary interventions.
\end{abstract}

Keywords: MANTRELS, Alvarado score, acute appendicitis, negative appendectomy

\section{Sergiu Chirila}

Faculty of Medicine, University "Ovidius" of Constanta Universitatii Alle No. 1, Campus B

Constanta, Romania

email : sergiu.chirila@univ-ovidius.ro phone: +40 721332068

\section{Introduction}

In spite of the fact that appendicitis represents the most common abdominal surgical emergency, the diagnosis of acute appendicitis, especially in the case of children, poses a significant problem even for the most experienced doctors.

Because of the symptomatology, which is common to other child specific diseases, the difficulty of gathering anamnestic information and perform the clinical examination, the diagnosis of acute appendicitis is a difficult one.

The rapid evolution towards complications and the associated occasional mortality transforms acute appendicitis in a diagnosis that needs an accurate and fast diagnosis.

Often, the surgeon that consults the patients is facing a dilemma:

- Wait for clear manifestations of the disease - and in this way it favors the development of complications such as perforation, intraperitoneal abscesses, generalized peritonitis, etc. All of these increase hospitalization costs, have a negative impact on the family and the child and increases the risk for accusations of malpraxis.

- Intervention with no delay, even before 
having a definitive diagnosis - increases negative appendectomies proportion, with unsound material costs and patient's exposure to anesthetic and surgical unnecessary risks.

Ideally the therapeutic decision should be taken soon enough to prevent the evolution towards complications, but at the same time with sufficient arguments in order to limit the rate of negative appendectomies.

The clinical manifestations of acute appendicitis are complex, with different associated signs and symptoms depending on the evolution of the condition, topography of the affected organ and the age of the patient.

For increasing the accuracy of the diagnosis of acute appendicitis, different scoring systems have been developed. These scores summarize anamnestic information, symptoms, clinical signs and laboratory data, each of those with different diagnostic values. Based on the value obtained a stratification of the risk the patients have and therapeutic indications a medical decision can be taken (discharge, clinical follow-up, complementary investigations, immediate surgical treatment).

The development of imagistic methods of diagnosis in the last decades play an important role in the diminishing value scoring systems have. On the other side, the limits of imagistic methods in diagnosing acute appendicitis, referring to ultrasonography (operator dependent, weak performance in diagnosing complicated conditions of non-inflamed appendices) and computer tomography (high costs, radiation exposure, long time to investigate and have the results) led to an increased interest in the last years for scoring systems $[1,2,3]$.

The most commonly used and well known scoring systems for acute appendicitis are the ones developed by Alvarado (MANTRELS score) and Samuels (PAS) $[4,5]$.

In this study, we evaluate the potential benefits of routinely using MANTRELS score with the purpose of avoiding unnecessary surgical interventions in children for the diagnosis of acute appendicitis.

\section{Material and method}

The study was conducted on a series of consecutive patients admitted with the diagnosis of acute appendicitis in the wards of General Surgery and Pediatric Surgery and Orthopedic from the Emergency County Hospital Piatra Neamt between 01.01.2009 and 31.12.2011

Because the medical facility doesn't have an emergency line for pediatric surgical emergencies, some of the patients are evaluated and treated both by general surgeons and pediatric surgeons.

Inclusion criteria:

- Pediatric patients admitted with suspicion of acute appendicitis

- Cases are included in a consecutive series

Exclusion criteria:

- Patients below the age of 4 (28 cases were excluded)

- Patients with appendicular plastron (14 cases were excluded)

- Patients with incomplete data (75 cases were excluded)

- Patients without surgical intervention (128 cases were excluded)

After applying the inclusion and the exclusion criteria, the total number of patients included in the study was 572 .

The main source of information were the medical records of the patients, operatory records and anatomopathological examination records.

We analyzed the existing data in order to identify the percentage of patients with negative appendectomies. For all patients the MANTRELS score was calculated. We retrospectively applied the score for each patient in order to identify the risk for acute appendicitis.

Confirmed diagnosis of acute appendicitis is done according to the result from the anatomopathological examination, and in cases where this was not conducted based on the macroscopic appearance described by the surgeon who performed the intervention.

During the analysis we grouped the patients 
into three groups according to the MANTRELS score we calculated. The first group is represented by patients with a score lower than 7 . These patients are considered as being unlikely (for scores less than 4 ) or with a small probability of acute appendicitis. The second group is represented by patients with a score of 7 or 8 , in this case the probability of acute appendicitis being high and patients with a score of 9 or 10 , in this case the diagnosis of acute appendicitis being very probable.

\section{Results}

The study was conducted on 572 patients that underwent appendectomy intervention. Almost $60 \%$ of the patients were males; the average age was 12.4 years old and a standard deviation of 3.52 years. The minimum age for the study was 4 and the maximum age 18 . (Table I)

Table I demographic characteristics of the patients

\begin{tabular}{lrrr} 
Age & \multicolumn{3}{c}{ Gender } \\
\cline { 2 - 4 } & \multicolumn{1}{c}{ Males } & Females & \multicolumn{1}{c}{ Total } \\
\hline \hline Mean & 11.53 & 12.98 & 12.40 \\
$\mathrm{~N}$ & 230 & 342 & 572 \\
Std. Deviation & 3.584 & 3.357 & 3.520 \\
Median & 12.00 & 14.00 & 13.00 \\
Range & 14 & 14 & 14 \\
Minimum & 4 & 4 & 4 \\
Maximum & 18 & 18 & 18 \\
\hline \hline
\end{tabular}

From the total number of patients included in this study, 16.3\% (Figure 1) were not confirmed as having had acute appendicitis. These are the cases we consider negative appendectomies.

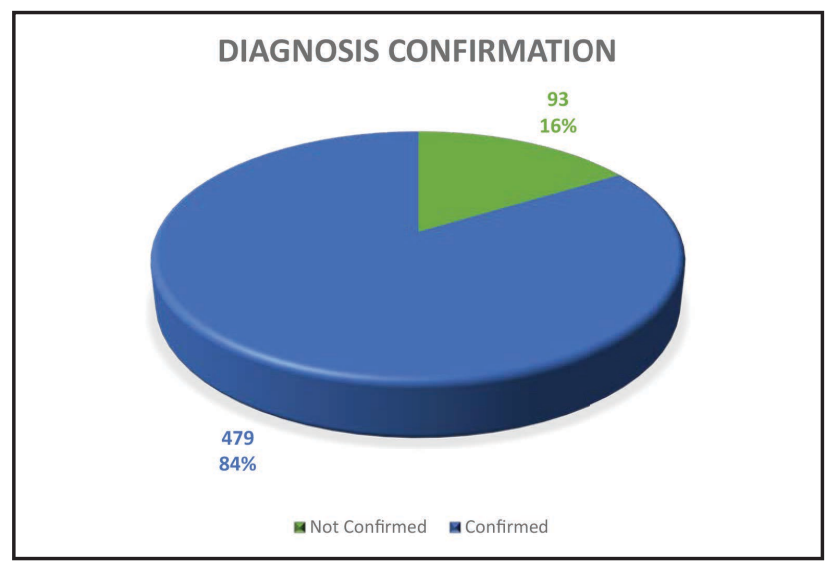

Figure 1 Diagnosis confirmation

According to the calculated appendicitis score, the scores were between 4 and 10. The highest number of patients had scores of 7 and 6 (Figure 2)

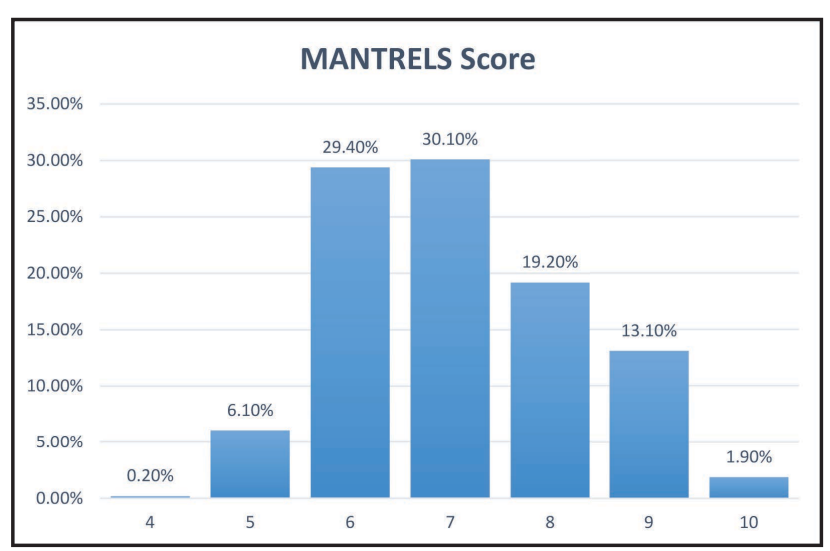

Figure 2 Distribution of the patients according to MANTRES Score

According to the groups used and defined in the material and methods part, $35.7 \%$ have a score of maximum 6 points, almost half (49.3\%) have a score of 7 or 8 and $15 \%$ of the patients have a score of 9 or 10 .

We compared the distribution of the patients included in this study according to the confirmation of the diagnosis and the score we calculated retrospectively. In the case of patients with unconfirmed diagnosis, almost $60 \%$ of them had a MANTRELS score of less or equal 
to 6, while in the case of confirmed cases the percentage is half of that, with $31.1 \%$. For the group of patients with high MANSTREL scores almost all of the patients have a confirmed diagnosis after surgical intervention (Table II, Figure 3).

Table II Distribution of the patients according to MANTRELS score and diagnosis confirmation

\begin{tabular}{|c|c|c|c|c|c|}
\hline \multirow{2}{*}{$\begin{array}{l}\text { No } \\
\text { Yes }\end{array}$} & & & \multicolumn{2}{|c|}{ Confirmed } & \multirow[b]{2}{*}{ Total } \\
\hline & & & & & \\
\hline \multirow{6}{*}{$\begin{array}{l}\text { MANTRELS } \\
\text { Score Group }\end{array}$} & $\leq 6$ & Count & 55 & 149 & 204 \\
\hline & & $\begin{array}{l}\% \text { within } \\
\text { Confirmed }\end{array}$ & $59.1 \%$ & $31.1 \%$ & $35.7 \%$ \\
\hline & $7-8$ & Count & 36 & 246 & 282 \\
\hline & & $\begin{array}{l}\% \text { within } \\
\text { Confirmed }\end{array}$ & $38.7 \%$ & $51.4 \%$ & $49.3 \%$ \\
\hline & $>8$ & Count & 2 & 84 & 86 \\
\hline & & $\begin{array}{l}\% \text { within } \\
\text { Confirmed }\end{array}$ & $2.2 \%$ & $17.5 \%$ & $15.0 \%$ \\
\hline \multirow[t]{2}{*}{ Total } & & Count & 93 & 479 & 572 \\
\hline & & $\begin{array}{l}\% \text { within } \\
\text { Confirmed }\end{array}$ & $100.0 \%$ & $100.0 \%$ & $100.0 \%$ \\
\hline
\end{tabular}

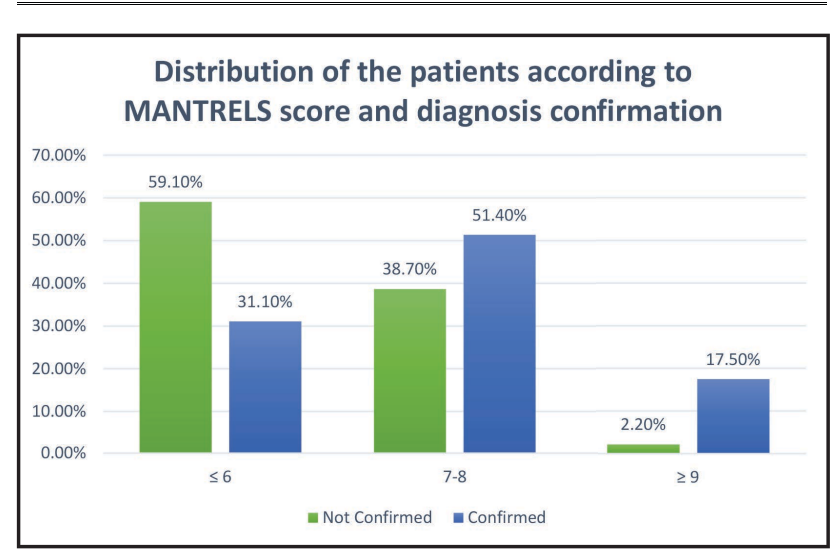

Figure 3 Distribution according to MATRELS score and diagnosis confirmation

The difference is statistically significant $(p<0.001)$ (Table I), with a high proportion of patients with negative appendectomies and a low MANTRELS score.
Table III Test of association between MANTRELS score and diagnosis

\begin{tabular}{llll}
\hline \hline & & & $\begin{array}{l}\text { Asymptotic } \\
\text { Significance } \\
\text { (2-sided) }\end{array}$ \\
\hline Pearson Chi-Square & $31.950 \mathrm{a}$ & 2 & 0.000 \\
$\begin{array}{l}\text { Likelihood Ratio } \\
\text { Linear-by-Linear }\end{array}$ & 35.655 & 2 & 0.000 \\
$\begin{array}{l}\text { Association } \\
\text { N of Valid Cases }\end{array}$ & 31.557 & 1 & 0.000 \\
$\begin{array}{l}\text { a. } 0 \text { cells }(0.0 \%) \text { have expected count less than 5. The } \\
\text { minimum expected count is 13.98. }\end{array}$
\end{tabular}

Looking at the data from a different point of view, $27 \%$ of the patients with a score of maximum 6 had negative appendectomies. In the case of patients with a higher score the percentage decreases significantly to $12.8 \%$ and in the case of patients with very high scores the percentage is very small, $2.3 \%$.

\section{Discussion}

In 1986 Alfred Alvarado published the best known and most studied score for acute appendicitis. It was a retrospective study on 305 patients admitted with suspicion of acute appendicitis, which correlates the clinical and laboratory results criteria with histopathological confirmed diagnosis [4]. After the sensibility and specificity were calculated, the predictive value of each criteria used for diagnosis, six clinical criteria and two laboratory criteria were included in the calculated score. 
Migration of pain to the right lower quadrant 1 point

Anorexia

1 point

Nausea or vomiting

Right lower quadrant tenderness

Rebound tenderness (Bloomberg sign)

Elevated temperature $(>37.30 \mathrm{C})$

Leukocytosis $(>10000 / \mathrm{mm} 3)$

Leukocyte left shift (>75\%)

A popular mnemonic of the criteria that make the Alvarado score in MANTRELS, where $\mathrm{M}=$ migration to the right ilia fossa, $\mathrm{A}=$ anorexia, $\mathrm{N}=$ nausea/vomiting, $\mathrm{T}=$ tenderness in right iliac fossa, $\mathrm{R}=$ rebound pain, $\mathrm{E}=$ elevated temperature, $\mathrm{L}=$ leukocytosis and $\mathrm{S}=$ shift of leukocytes to the left. Because of this, most of the studies cite and use the term of MANTRELS score instead of Alvarado score.

Diagnostic relevance of the right lower quadrant tenderness and leukocytosis were considered more important, therefore these were granted 2 points each. All other criteria considered have 1 point each. Maximum score is 10 .

A score of 5-6 is compatible with acute appendicitis, a score of 7-8 indicates probable acute appendicitis, while a score of 9-10 it's indicator for very probable acute appendicitis.

According to the calculated score, Alvarado proposed the following actions:

- Exclude the diagnosis if the value is below 4

- Clinical observation for scores of 5 and 6

- Surgical intervention for scores 7 to 10 .

After it was published a series of other studies that evaluated the performance Alvarado score offers. Alfred Bond [6], Escriba [7], Dado [8] consider the performance of the score as being very good, while others like Macklin [9], Hsiao [10[, Schneider [11] consider the results as being modest.

\section{Conclusions}

Using the Alvarado score can be a very useful instrument for diagnosing acute appendicitis in early stages of the disease, especially when the score is below 4 or above 8 .

It is a very simple, fast, noninvasive, reproducible test, which doesn't require any additional costs. It can reduce the need for imagistic investigations, especially for patients with a very low score, for which the suspicion for acute appendicitis can be excluded, while for values higher than eight, case in which the diagnosis is almost certain and immediate surgical intervention is indicated. This is a very useful tool especially for hospitals with lower financial resources.

It also represents a very useful tool for doctors in the Emergency Unit, for junior surgeons and for general practitioners.

Being a scoring system minimizes the subjective factors related to the observer, such as professional experience, recent negative experiences with similar cases, fear of different accusations, stress.

In our study we observed that almost one third of the patients with a score lower than 6 present negative appendectomies, representing almost $60 \%$ from the total number of patients with negative appendectomies.

Unfortunately, for scores between 5 and 8 the therapeutic decision is more difficult. In this case a thorough examination, with repeated evaluations in time, imagistic explorations and professional experience.

\section{References}

1. McKay, R. \& Shepherd, J. (2007). The use of the clinical scoring system by Alvarado in the decision to perform computed tomography for acute appendicitis in the ED. Am J Emerg Med, 25(5), 489-493. doi: 10.1016/j. ajem.2006.08.020

2. Cobben, L., Groot, I., Kingma, L., Coerkamp, E., Puylaert, J. \& Blickman, J. (2009). A simple MRI protocol in patients 
with clinically suspected appendicitis: results in 138 patients and effect on outcome of appendectomy. Eur Radiol, 19(5), 11751183. doi: 10.1007/s00330-008-1270-9

3. Tzanakis, N.E., Efstathiou, S.P., Danulidis, K., Rallis, G.E., Tsioulos, D.I., Chatzivasiliou, A., Peros, G. \& Nikiteas, N.I. (2005). A new approach to accurate diagnosis of acute appendicitis. World J Surg, 29(9), 11511156, discussion 1157. doi: 10.1007/s00268005-7853-6

4. Alvarado, A. (1986). A practical score for the early diagnosis of acute appendicitis. Ann Emerg Med, 15(5), 557-564.

5. Samuel, M. (2002). Pediatric appendicitis score. J Pediatr Surg, 37(6), 877-881.

6. Bond, G.R., Tully, S.B., Chan, L.S. \& Bradley, R.L. (1990). Use of the MANTRELS score in childhood appendicitis: a prospective study of 187 children with abdominal pain. Annals of Emergency Medicine, 19(9), 1014-1018. doi: 10.1016/s0196-0644(05)82566-1

7. Escriba, A., Gamell, A.M., Fernandez, Y., Quintilla, J.M. \& Cubells, C.L. (2011). Prospective validation of two systems of classification for the diagnosis of acute appendicitis. Pediatr Emerg Care, 27(3), 165169. doi: 10.1097/PEC.0b013e31820d6460
8. Dado, G.,Anania, G., Baccarani, U., Marcotti, E., Donini, A., Risaliti, A., Pasqualucci, A. \& Bresadola, F. (2000). Application of a clinical score for the diagnosis of acute appendicitis in childhood: a retrospective analysis of 197 patients. J Pediatr Surg, 35(9), 1320-1322. doi: 10.1053/jpsu.2000.9316

9. Macklin, C.P., Radcliffe, G.S., Merei, J.M. \& Stringer, M.D. (1997). A prospective evaluation of the modified Alvarado score for acute appendicitis in children. Ann R Coll Surg Engl, 79(3), 203-205.

10. Hsiao, K.H., Lin, L.H. \& Chen, D.F. (2005). Application of the MANTRELS scoring system in the diagnosis of acute appendicitis in children. Acta Paediatr Taiwan, 46(3), 128-131.

11. Schneider, C., Kharbanda, A. \& Bachur, R. (2007). Evaluating appendicitis scoring systems using a prospective pediatric cohort. Ann Emerg Med, 49(6), 778-784, 784.e771. doi: 10.1016/j.annemergmed.2006.12.016 